\title{
Is Laparoscopic Technique Suitable for Initial Experience in Live Donor Nephrectomy? Results of The First 51 Cases
}

\author{
Emrah Akin ${ }^{1 \star}$, Fatih Altintoprak ${ }^{2}$, Necattin Firat ${ }^{2}$, Hamad Dheir ${ }^{3}$, Enes Bas ${ }^{1}$, Taner Demirci ${ }^{4}$, Burak Kamburoglu ${ }^{1}$, \\ Fehmi Celebi ${ }^{2}$
}

\author{
${ }^{1}$ Sakarya University Educational and Research Hospital, Department of General Surgery, Sakarya, TURKEY \\ ${ }^{2}$ Sakarya University Faculty of Medicine, Department of General Surgery, Sakarya, TURKEY \\ ${ }^{3}$ Sakarya University Faculty of Medicine, Department of Nephrology, Sakarya, TURKEY \\ ${ }^{4}$ Sakarya University Faculty of Medicine, Department of Endocrinology, Sakarya, TURKEY \\ *Corresponding Author: emrahakin@sakarya.edu.tr
}

Citation: Akin E, Altintoprak F, Firat N, Dheir H, Bas E, Demirci T, Kamburoglu B, Celebi F. Is Laparoscopic Technique Suitable for Initial Experience in Live Donor Nephrectomy? Results of The First 51 Cases. Electron J Gen Med. 2021;18(6):em326. https://doi.org/10.29333/ejgm/11313

\section{ARTICLE INFO}

Received: 10 Jul. 2021

Accepted: 16 Oct. 2021

\section{ABSTRACT}

Objective: Laparoscopic donor nephrectomy is included in advanced laparoscopic surgical procedures and is the most preferred method for live donor nephrectomy. It is discussed that teams who do not have experience with live donor nephrectomy prefer the laparoscopic method for the first experience in kidney transplantation. The present manuscript is aimed to present the results of laparoscopic live donor nephrectomy who's the first 51 cases of a surgical team without any experience of open donor nephrectomy.

Method: The medical records of donor nephrectomy which laparoscopic surgery was performed between April 2019-August 2020 reviewed retrospectively. Demographic features, routine transplantation preoperative data, donor nephrectomy side and reasons, surgical technique details, operation time, warm ischemia time, postoperative laboratory parameters, hospitalization time, early morbidity results were evaluated in detail.

Result: Results of 51 donors between the specified dates were evaluated. The mean age of the patients was 44.6 \pm 11.6 (22-69) years. The patients' $\mathrm{K} / \mathrm{E}$ ratio was $25 / 26$. The number of patients with $\mathrm{BMI} \geqslant 30$ was $14(27.4 \%)$. Right nephrectomy was performed on ten donors (19.6\%). The mean operative time of the patients was $130 \mathrm{~min}$. (120$160)$, and the mean warm ischemia time was $149 \mathrm{sec}$. (113-180). Postoperative complications were in 4 patients (7.8\%).

Conclusion: The laparoscopic method for live donor nephrectomy may be applied in safe from the initial stage by teams with advanced minimally invasive surgery experience.

Keywords: transabdominal, laparoscopic nephrectomy, donor nephrectomy, live donor nephrectomy

\section{INTRODUCTION}

Renal transplantation (RT) is considered the best treatment option in last stage kidney failure and promises better survival rates than dialysis [1]. This better survival is due to improvements in surgical technique, increased quality in postoperative care and the introduction of individualized immunosuppressive treatment protocols and had improved transplant results [2]. Live donor nephrectomy (LDN), wherefore it is a surgical technique related to the main vascular structures, has the possibility of postoperative complications, and is a considerable surgical procedure because the people to whom the procedure is applied are healthy individuals.

The minimally invasive technique has come to the fore in RT as in all other surgeries, and since the first laparoscopic nephrectomy (LN) surgery had performed in 1995, they have been started to be recommended as the standard method today [3-6]. The rates of laparoscopic live donor nephrectomy increased from $28 \%$ to $43 \%$ between 1993-2002, and the increasing rate was $11 \%$ only between $2000-2001$ [7]. In the current literature the $\mathrm{LN}$ is the gold standart method for live donors [8]. However, there is no consensus about for the first experience to start RT teams [9]. The present study is aimed to exhibit the results of a surgical team that had performed LDN operations initially and the appropriateness of the laparoscopic method for beginners for the surgical procedure is discussed also early surgical results are discussed in the light of current literature data.

\section{MATERIALS AND METHODS}

This study was approved by the Sakarya University Ethics Committee (No:71522473/050.01.04/503) and was complied with the 1964 Helsinki declaration and its later amendments. Medical records of LDN surgeries performed in Sakarya University Faculty of Medicine, Department of General Surgery were retrospectively reviewed. While evaluating the eligibility criteria for LDN candidates, adults with compatible ABO blood group, normotensive systemic blood pressure, no DM or nonurological anomaly, acceptable HLA match and without 


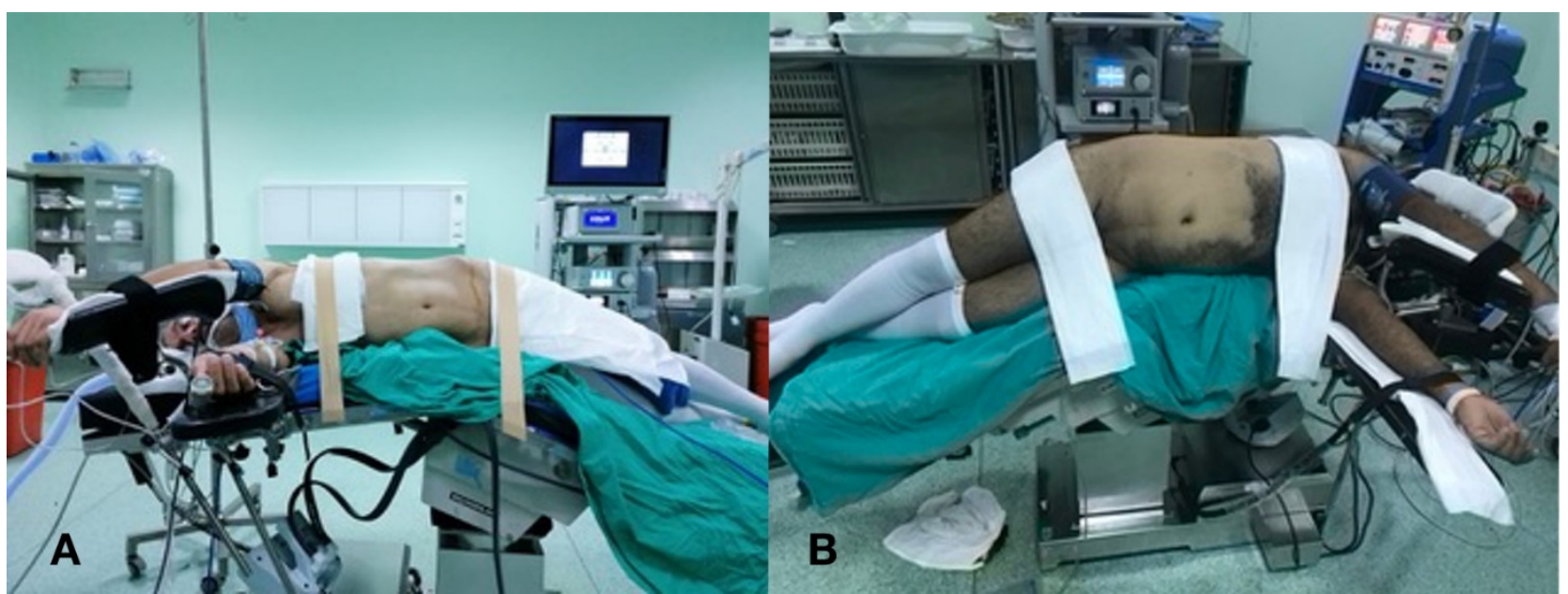

Figure 1. Laparoscopic donor nepfrectomy positions A) right lateral decubitis B) left lateral decubitis

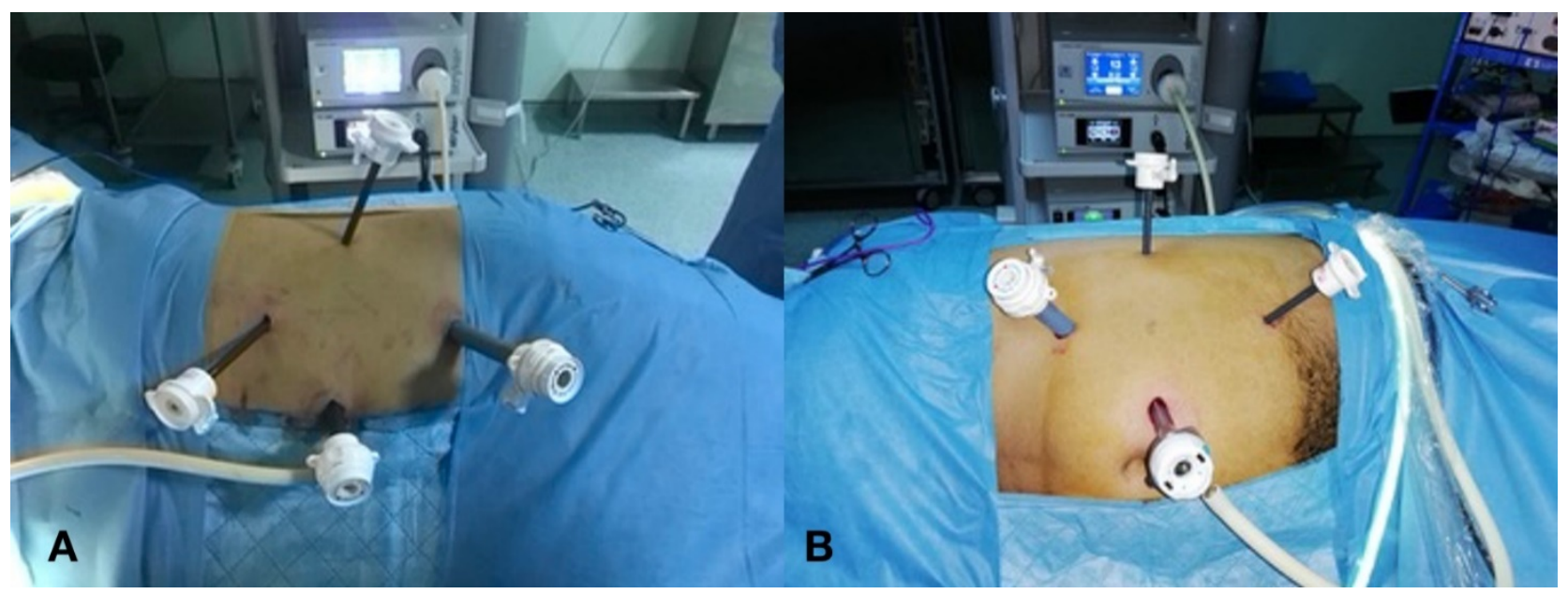

Figure 2. Laparoscopic donor nephrectomy trocar places A) left donor nephrectomy B) right donor nephrectomy

any systemic disease, and negative crossmatch were accepted as suitable donors. All donors were informed in LDN and live donor renal transplantation procedures, and their consents were obtained. In the preoperative period, LDN candidates had psychiatric evaluation, CT angiography was performed to reveal the renal vascular anatomy. In the absence of a renal parenchymal or vascular obstruction, extraction of the left kidney was preferred. Patient demographic characteristics, BMI level of proximity to the recipient, HLA compatibility, donor kidney side, renal vascular and ureteral system variations, hot-cold ischemia time, bleeding volume, postoperative complication rates, hospitalization day and need for re-operation were examined.

\section{Surgical Technique}

Operations were performed in the lateral decubitus position as shown in Figure $\mathbf{1 A}$ and $\mathbf{1 B}$.

The first $10 \mathrm{~mm}$ trocar was placed into the abdomen with lateralized periumblical mini incision and Hasson technique, than a total of 3 more trocars of $15 \mathrm{~mm}$ and 2, $5 \mathrm{~mm}$ were placed with direct vision as shown in Figure $2 \mathrm{~A}$ and $2 \mathrm{~B}$.

For left nephrectomy, the splenic flexure was mobilized and the colon was tilted over medially. After releasing of the ureter and gonadal vascular structures on the left, the Gerota fascia was opened and the renal vein and renal artery were exposed. The next step was the separation of the perinephritic fatty tissue and the disruption of the splenorenal ligament and the overturning of the kidney to the medial and the $15 \mathrm{~mm}$ port was turned into an $8 \mathrm{~cm}$ incision with the peritoneum safe. Gonadal vessels were closed and cut with hem-o-lock vascular clips $^{\circledR}$ (Wech; Teleflex Inc., Limenich, PA, USA). The ureter was closed with a double hem-o-lock vascular clip and cut. The renal artery and renal vein were closed and cut, respectively, using an Endo-GIA III vascular stapler ${ }^{\circledR}$ (Autosuture; US surgical, Norwach, $\mathrm{Cl}$, USA) with $30 \mathrm{~mm}-2.5 \mathrm{~mm}$, 3-row punch technology. The kidney was taken out of the abdomen by enlarging the suprapubic incision with the hand force, and perfused with Ringer's lactate infusion. The layers were closed in the anatomical plan and the abdomen desufled. After the bleeding control, a Jacksonn-Pratt silicone drain was placed via by a $5 \mathrm{~mm}$ trocar space and the surgery was terminated. When extracting the right kidney, unlike this order an additional $5 \mathrm{~mm}$ trocar was inserted for the liver retractor, the gonadal vein on the right was protected, other maneuvers were performed in the same technique.

\section{Statistical Analysis}

Data analysis was performed by using SPSS-22 for Windows (Statistical Package for Social Science, SPSS Inc. Chicago IL, $\mathrm{USA}^{\circledR} \mathrm{Z}$ ). The variables were investigated using visual (histograms, probability plot) and analytical methods (Kolmogorov-Simirnov/Shapiro-Wilk's test) to determine whether or not they are normally distributed. We performed 
Table 1. Preoperative clinical and demographic features

\begin{tabular}{lc}
\hline & Results $^{\star}(\mathbf{n}=\mathbf{5 1})$ \\
\hline Age, years (min-max) & $44.6 \pm 11.6(22-69)$ \\
\hline Gender, $\mathrm{F} / \mathrm{M}, \mathrm{n}(\%)$ & $25 / 26(49 / 51)$ \\
\hline BMI, $\mathrm{kg} / \mathrm{m}^{2}$ & $27.34 \pm 4.81$ \\
Obesity, $\mathrm{n}(\%)$ & $14(27.4)$ \\
\hline Relationship, $\mathrm{n}(\%)$ & \\
$1^{\text {st }}$ degree relative & $36(70.6)$ \\
$2^{\text {nd }}$ degree relative & $13(25.5)$ \\
$3^{\text {rd }}$ degree relative & $1(2.0)$ \\
$4^{\text {th }}$ degree relative & $1(2.0)$ \\
\hline Blood group, $\mathrm{n}(\%)$ & \\
A Rh (+) & $17(33.3)$ \\
A Rh (-) & $1(2.0)$ \\
B Rh (+) & $2(3.9)$ \\
B Rh (-) & $1(2.0)$ \\
0 Rh (+) & $25(49.0)$ \\
0 Rh (-) & $5(9.8)$ \\
\hline Glomerular filtration rate, & \\
mL/min/1,73 m ${ }^{2}$ & $111.0 \pm 11.7$ \\
at admission & $75.0 \pm 18.2$ \\
at discharge & $\mathbf{p}<0.001$ \\
statistical difference &
\end{tabular}

Abbreviation: BMI; body mass index.

${ }^{*}$ Continuous variables were expressed as means \pm standard deviation and categorical variables as numbers with percentages for the description of baseline characteristics.

analyses to describe and summarize the distributions of variables. Student's t test was used to compare normally distributed variables such as GFR results at admission and discharge. In addition, Repeated measures ANOVA (general linear model) method was used to compare different period results such as creatinine results. The statistically significant two tailed $p$-value was considered as $<0.05$.

\section{RESULTS}

Fifty-one LDN operations were performed between April 2019 and August 2020 by the team with more than 200 advanced laparoscopically surgery experience in minimal invasive techniques annually in a tertiary medical faculty hospital. The mean age of donors was $44.6 \pm 11.6$ (22-69) years and 25 patients (49\%) were women. Thirty-six of the donors $(70.6 \%)$ were $1^{\circ}$ relative of the recipient. Preoperative parameters are shown in Table 1.

Left nephrectomy (80.4\%) was performed in 41 donors. The mean operation time was 130 minutes (120-160) and warm ischemia time was 149 seconds (113-180) mean. The patients were discharged on the third postoperative day. HLA tissue compatibility among the recipient-donors was most common in $3 / 6$ and was seen in 17 transplants (33.3\%). There were double arteries in 7 (13.7\%) of the donor kidneys, double veins in $2(3.9 \%)$ and three veins in $1(2 \%)$ donor. Lumbar vein was present in $18(35.5 \%)$ of the patients, all lumbar veins were closed with hem-o-lock clips. A double ureteral system was in one patient (2\%). In the postoperative period, 1 patient (1.9\%) was re-operated due to bleeding, active bleeding was not detected. Chylous acid (1.9\%) fluid was detected from the drain as a complication in one patient, the patient was followed up conservatively, the drain was removed on the 12th day after spontaneous regression. In one patient, graft dysfunction occurred due to diffuse venous thrombosis on the postoperative 1st day and the transplanted kidney was
Table 2. Perioperative and postoperative parameters of renal transplant donors

\begin{tabular}{|c|c|}
\hline & Results $^{\star}(n=51)$ \\
\hline \multicolumn{2}{|l|}{ Donated kidney side, $n(\%)$} \\
\hline Left & $41(80.4)$ \\
\hline Right & $10(19.6)$ \\
\hline Surgical time, minutes & $130(120-160)$ \\
\hline Warm ischemia time, second & $149(113-180)$ \\
\hline Cold ischemia time, minutes & $65(59-80)$ \\
\hline Length of hospital stay, days & $3(3-3)$ \\
\hline \multicolumn{2}{|l|}{ HLA tissue compatibility, $n$ (\%) } \\
\hline Full antigen (6) match & $6(11.8)$ \\
\hline 1 antigen mismatch & $2(3.9)$ \\
\hline 2 antigen mismatch & $7(13.7)$ \\
\hline 3 antigen mismatch & $17(33.3)$ \\
\hline 4 antigen mismatch & $3(5.9)$ \\
\hline 5 antigen mismatch & $7(13.7)$ \\
\hline Full antigen (6) mismatch & $9(17.6)$ \\
\hline \multicolumn{2}{|l|}{ Anatomical abnormalities } \\
\hline \multicolumn{2}{|l|}{ Number of arteries, } \\
\hline $1, n(\%)$ & $44(86.3)$ \\
\hline $2, n(\%)$ & $7(13.7)$ \\
\hline \multicolumn{2}{|l|}{ Number of veins } \\
\hline $1, n(\%)$ & $48(94.1)$ \\
\hline $2, n(\%)$ & $2(3.9)$ \\
\hline $3, n(\%)$ & $1(2.0)$ \\
\hline \multicolumn{2}{|l|}{ Number of ureters } \\
\hline $1, n(\%)$ & $50(98)$ \\
\hline $2, n(\%)$ & $1(2)$ \\
\hline Lumbar vein presence, $\%$ & $18(35.3)$ \\
\hline \multicolumn{2}{|l|}{ Postoperative complications } \\
\hline Reopen for bleeding from ureteral artery, $n(\%)$ & $1(1.9)$ \\
\hline Transplant organ rejection & $1(1.9)$ \\
\hline Chylous leak, $n$ (\%) & $1(1.9)$ \\
\hline ileus, $n(\%)$ & $1(1.9)$ \\
\hline
\end{tabular}

removed. Perioperative-postoperative parameters are shown in Table 2. While glomerular filtration rates of donors were measured as $111.0 \pm 11.7 \mathrm{ml} / \mathrm{min} / 1.73 \mathrm{~m}^{2}$ in the preoperative period and $75.0 \pm 18.2 \mathrm{ml} / \mathrm{min} / 1.73 \mathrm{~m}^{2}$ after nephrectomy, there is no statistically significant difference between the two measures $(p<0.001)$ as shown in Table 2.

There is no statistically significant difference in the creatinine levels of the donors on the postoperative 1st, 2nd and $3 r d$ days $(p<0.001)$. Postoperative creatinine levels are shown in Figure 3.

\section{DISCUSSION}

Since sufficient number of cadaver transplants could not be performed in transplantation surgery to meet the increasing demand for kidney graft, it has become inevitable to move towards live donor kidney transplantation worldwide. Live donor nephrectomy technique has evolved from classical open nephrectomy to minimally invasive laparoscopic-robotic techniques with muscle-sparing mini-incision [10]. In an international report examined global live donor kidney transplantation trends in sixty-nine countries; it has been reported that in $62 \%$ of the countries, more than $50 \%$ of the transplants were performed with live donor nephrectomy in the last 10 years [11]. While the rate of live donor transplantation is $67.6 \%$ in Western countries, this rate is more than $95 \%$ in Asia and the Middle East $[12,13]$. Republic of 


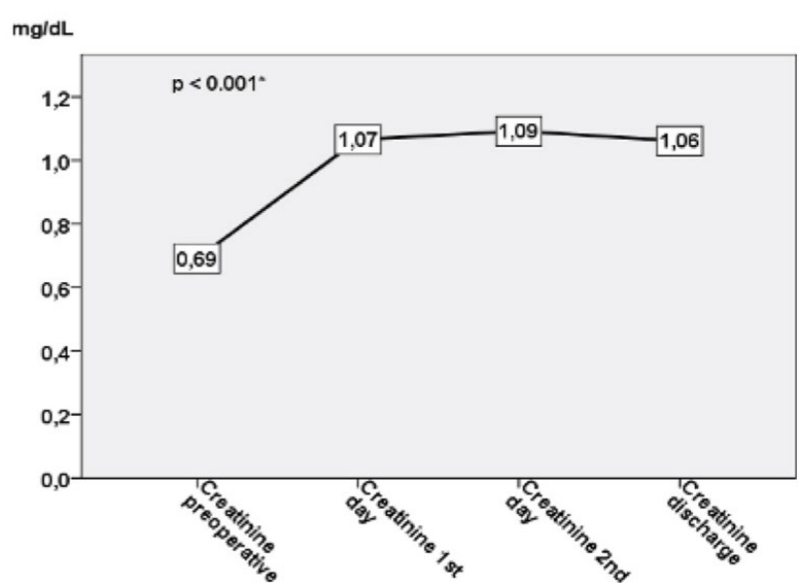

Figure 3. The change in creatinine level was shown for the preand post-operative period

* The statistical difference is due to the preoperative mean of creatinine. There is no difference between the other period creatinine averages

Turkey Ministry of Health in our country live donor transplant rate is reported as $87 \%$ according to 2018 data [14]. Nowadays, minimally invasive methods are the most preferred option for kidney transplants with living donors [15]. These techniques offer well-known advantages such as faster return to work, shorter hospital stay, less postoperative pain, better cosmetic results. While the technique has hand-assisted, endolaparoscopic retroperitoneal, full laparoscopic and robotassisted variations, LDN has gained popularity due to its transabdominal and conventional laparoscopic instruments. In a meta-analysis approximately 32,000 cases were evaluated and with a rate of $57.4 \%$, LDN became the most preferred method at the international level [16]. Additionally in a recent study with 2477 case showed that the technique was suitable for the beginner transplant surgeons [17].

In the early periods when minimally invasive technique was used, there were fears about decreased allograft quality due to higher surgical risk, longer operation time, possible damage to graft function, and the possibility of more urinary complications compared to open technique [18]. With the development of technology, the widespread use of the technique and the increase in experience, it has been shown by randomized controlled studies and meta-analyzes that the results of minimally invasive methods are similar to the open method and that these fears are unfounded [19-21]. In addition early meta analysis of randomized controlled trials shown that with enhanced recovery after surgery (ERAS) protocols living donor nephrectomy is feasible and safety [22].

Complex venous variations such as circumaortic veins, retroaortic veins, multiple renal veins or multiplex lumbar vein draining into the left renal vein can be observed in the renal vascular anatomy. According to the study of Deak et al. in laparoscopic live kidney transplantation it is recommended to prefer left nephrectomy instead of right because of shorter renal vessels in general [23]. Bachir et al. reported that the results for donors and recipients did not change according to the side of the kidney taken [24]. Also, in our own experiences if there was a single artery on both sides, our preference was to perform left nephrectomy (39 donors-78\%). We chose to take the left kidney if there are multiple arteries in both kidneys, and the right kidney if there are two arteries on the left and one on the right. In the presence of incidental minor anomalies such as simple cysts, we preferred to remove the kidney with anomaly in order to keep the healthy kidney in the living donor.

In the literature, rates varying between $0.3 \%$ and $0.01 \%$ are reported for mortality after donor nephrectomy [16]. Major intra-abdominal hemorrhage is cited as the main cause of mortality. In the studies of Simfroosh et al including 1834 cases where vascular clips were used for vascular control; The bleeding rate has been reported at a rate of $0.2 \%$, it has been reported that the bleeding is caused by pseudo-aneurysms in the renal artery. According to the results of this study, it has been reported that the clips save $\$ 670$ per case in the long term and are a safe and cost-saving option for vascular control in the hands of trained surgeons [25]. However, in the study published by Friedmann et al. in 2011, it has been reported that clips should not be used to control the donor renal artery, and all surgeons working on a living organ donor should choose safer vascular techniques that require tissue transfection [26]. We preferred the use of staplers for vascular control in our patients, and in our experience, we did not encounter subscriber hemorrhage and mortality.

There is more than one study in the literature evaluating the perioperative and short-term morbidity of more than 1000 LDN patient [27-30]. According to these studies, while the total complication rates of LDN including infection, ileus, arrhythmia and pneumonia varied between 5.6-7.9\%, conversion rates were reported as $0.3-0.9 \%$. While postoperative complications were detected in 2 patients (4\%), in our experience one incisional hernia and one ileus, none of our patients conversioned to open surgery. In the study about 2500 cases published by Rally et al., which is one of the largest LDN series published in the literature, mean operation time is 140 minutes, average warm ischemia times are 4.4 minutes for the left kidney and 5.2 minutes for the right kidney [31]. Our operation times and warm ischemia times seem to be compatible with the literature. These findings are particularly important as a strong correlation has been demonstrated between ischemia times and functional outcomes of the transplanted kidney [3].

The retrospective structure of the study and the smaller number of cases can be considered as its limitations.

\section{CONCLUSION}

Transabdominal laparoscopic donor nephrectomy technique, provided that experienced surgical team with graft survival and acceptable morbidity in donor transplantation can be safely applied also in the beginner's unit.

Author contributions: All authors have sufficiently contributed to the study, and agreed with the results and conclusions.

Funding: No funding source is reported for this study.

Declaration of interest: No conflict of interest is declared by authors.

\section{REFERENCES}

1. Guler S, Cimen S, Hurton S, Molinari M. Risks and benefits of early catheter removal after renal transplantation. Transplant Proc. 2015;47(10):2855-9. https://doi.org/ 10.1016/j.transproceed.2015.10.032 PMid:26707302 
2. Cimen S, Guler S, Alwayn I, Lawen J, Kiberd B. Correlation of surgical times with laparoscopic live donor kidney transplant outcomes. Open J Organ Transpl Surg. 2013;3(4):68-72. https://doi.org/10.4236/ojots.2013.34014

3. Ratner LE, Ciseck LJ, Moore RG, Cigarroa FG, Kaufman HS, Kavoussi LR. Laparoscopic live donor nephrectomy. Transplantation. 1995;60(9):1047-9.

4. Janki S, Dor FJMF, IJzermans JNM. Surgical aspects of live kidney donation: an updated review. Front Biosci Elite Ed. 2015;7:346-65. https://doi.org/10.2741/738 PMid:25553384

5. Nanidis TG, Antcliffe D, Kokkinos C, Borysiewicz CA, Darzi AW, Tekkis PP, et al. Laparoscopic versus open live donor nephrectomy in renal transplantation: a meta-analysis. Ann Surg. 2008 Jan;247(1):58-70. https://doi.org/ 10.1097/SLA.0b013e318153fd13 PMid:18156924

6. Wilson $\mathrm{CH}$, Sanni A, Rix DA, Soomro NA. Laparoscopic versus open nephrectomy for live kidney donors. Cochrane Database Syst Rev. 2011 Nov 9;(11):CD006124. https://doi.org/10.1002/14651858.CD006124.pub2 PMid:22071829

7. Cecka JM. The OPTN/UNOS Renal Transplant Registry 2003. Clin Transpl. 2003;1-12.

8. Garg AX, Levey AS, Kasiske BL, Cheung M, Lentine KL, KDIGO Clinical Practice Guideline on the Evaluation and Care of Living Kidney Donors Work Group and Evidence Review Team. Application of the 2017 KDIGO guideline for the evaluation and care of living kidney donors to clinical practice. Clin J Am Soc Nephrol CJASN. 2020;15(6):896-905. https://doi.org/10.2215/CJN.12141019ＰMid:32276946 PMCid:PMC7274294

9. Claisse G, Gaillard F, Mariat C. Living kidney donor evaluation. Transplantation. 2020;104(12):2487-96. https://doi.org/10.1097/TP.0000000000003242 PMid:32229773

10. Davis CL, Delmonico FL. Living-donor kidney transplantation: a review of the current practices for the live donor. J Am Soc Nephrol JASN. 2005;16(7):2098-110. https://doi.org/10.1681/ASN.2004100824 PMid:15930096

11. Horvat LD, Shariff SZ, Garg AX, Donor Nephrectomy Outcomes Research (DONOR) Network. Global trends in the rates of living kidney donation. Kidney Int. 2009;75(10):1088-98. https://doi.org/10.1038/ki.2009.20 PMid: 19225540

12. Reese PP, Boudville N, Garg AX. Living kidney donation: outcomes, ethics, and uncertainty. Lancet Lond Engl. 2015;385(9981):2003-13. https://doi.org/10.1016/S01406736(14)62484-3

13. optn_committee_initiatives_2014-15.pdf. Available at https://optn.transplant.hrsa.gov/media/1524/optn_comm ittee_initiatives_2014-15.pdf (Accessed: 10 July 2021).

14. TTDISKDS KAMU. Available at: https://organkds.saglik.gov. tr/dss/PUBLIC/Transplant_Kidney.aspx (Accessed: 10 July 2021).

15. Kok NFM, Weimar W, Alwayn IPJ, ljzermans JNM. The current practice of live donor nephrectomy in Europe. Transplantation. 2006;82(7):892-7. https://doi.org/10.1097 /01.tp.0000235511.19629.0d PMid:17038903

16. Kortram K, ljzermans JNM, Dor FJMF. Perioperative events and complications in minimally invasive live donor nephrectomy: A systematic review and meta-analysis. Transplantation. 2016;100(11):2264-75. https://doi.org/ 10.1097/TP.0000000000001327 PMid:27428715
17. Ozturk SA, Yuksel Y, Erbis H, Aliosmanoglu I, Sarier M, Yayar $\mathrm{O}$, et al. Laparoscopic live donor nephrectomy: Experience of high-volume center with 2,477 cases. Urol Int. 2021;105(1-2):100-7. https://doi.org/10.1159/000511377 PMid:33207353

18. Simforoosh N, Bassiri A, Ziaee S a. M, Tabibi A, Salim NS, Pourrezagholi F, et al. Laparoscopic versus open live donor nephrectomy: the first randomized clinical trial. Transplant Proc. 2003;35(7):2553-4. https://doi.org/10.1016/j.trans proceed.2003.08.062 PMid:14612012

19. Wadström J, Martin AL, Estok R, Mercaldi CJ, Stifelman MD. Comparison of hand-assisted laparoscopy versus open and laparoscopic techniques in urology procedures: a systematic review and meta-analysis. J Endourol. 2011;25(7):1095-104. https://doi.org/10.1089/end.2010. 0348 PMid:21740261

20. Troppmann C, Perez RV, McBride M. Similar long-term outcomes for laparoscopic versus open live-donor nephrectomy kidney grafts: an OPTN database analysis of 5532 adult recipients. Transplantation. 2008;85(6):916-9. https://doi.org/10.1097/TP.0b013e318166ad77 PMid:18360277

21. Bargman V, Sundaram CP, Bernie J, Goggins W. Randomized trial of laparoscopic donor nephrectomy with and without hand assistance. J Endourol. 2006;20(10):71722. https://doi.org/10.1089/end.2006.20.717 PMid: 17094745

22. Prionas A, Craddock C, Papalois V. Feasibility, safety and efficacy of enhanced recovery after living donor nephrectomy: Systematic review and meta-analysis of randomized controlled trials. J Clin Med. 2020;10(1):E21. https://doi.org/10.3390/jcm10010021 PMid:33374793 PMCid:PMC7795400

23. Deák PÁ, Doros A, Lovró Z, Toronyi E, Kovács JB, Végsö G, et al. The significance of the circumaortic left renal vein and other venous variations in laparoscopic living donor nephrectomies. Transplant Proc. 2011;43(4):1230-2. https://doi.org/10.1016/j.transproceed.2011.03.069 PMid:21620097

24. Bachir BG, Hussein M, Nasr R, Abu-Dargham R, Khauli RB. Evaluation of right versus left laparoscopic donor nephrectomy. Exp Clin Transplant Off J Middle East Soc Organ Transplant. 2011;9(5):310-4.

25. Simforoosh N, Sarhangnejad R, Basiri A, Ziaee SAM, Sharifiaghdas F, Tabibi A, et al. Vascular clips are safe and a great cost-effective technique for arterial and venous control in laparoscopic nephrectomy: single-center experience with 1834 laparoscopic nephrectomies. J Endourol. 2012;26(8):1009-12. https://doi.org/10.1089/ end.2011.0619 PMid:22332818

26. Friedman AL, Peters TG, Ratner LE. Regulatory failure contributing to deaths of live kidney donors. Am J Transplant Off J Am Soc Transplant Am Soc Transpl Surg. 2012;12(4):829-34. https://doi.org/10.1111/j.16006143.2011.03918.x PMid:22233486

27. Cho SJ, Moon HW, Kang S-M, Choi SW, Kim KS, Choi Y-S, et al. Evolution of laparoscopic donor nephrectomy techniques and outcomes: A single-center experience with more than 1000 cases. Ann Transplant. 2020;25:e918189. https://doi.org/10.12659/AOT.918189 
28. Treat EG, Schulam PG, Gritsch HA, Liu C-H, Xiong S, Passos $F$, et al. Evolution of laparoscopic donor nephrectomy technique and outcomes: a single-center experience with more than 1300 cases. Urology. 2015;85(1):107-12. https://doi.org/10.1016/j.urology.2014.09.027

PMid:25530372

29. Cooper M, Kramer A, Nogueira JM, Phelan M. Recipient outcomes of dual and multiple renal arteries following 1000 consecutive laparoscopic donor nephrectomies at a single institution. Clin Transplant. 2013;27(2):261-6. https://doi.org/10.1111/ctr.12062 PMid:23305411
30. Rajab A, Pelletier RP. The safety of hand-assisted laparoscopic living donor nephrectomy: the Ohio State University experience with 1500 cases. Clin Transplant. 2015;29(3):204-10. https://doi.org/10.1111/ctr.12501 PMid:25529029

31. Rally S, Sharma A, Singh S, Patil SS, Pandey GS, Kapoor K, et al. Experience with 15 years of laparoscopic donor nephrectomy: Review of 2500 cases. Transplant Proc. 2020;52(6):1671-4. https://doi.org/10.1016/j.transproceed. 2020.03.016 PMid:32448655 